\title{
STUDI KRITIKALITAS REAKTOR RISET DAYA RENDAH BERBAHAN BAKAR U $\mathrm{U}_{3} \mathrm{Si}_{2} \mathrm{Al}$
}

\section{CRITICALITY STUDY OF LOW POWER RESEARCH REAKTOR WITH $U_{3} \mathrm{Si}_{2} A I$ FUEL}

\author{
Tri Wulan Tjiptono \\ Pusat Sains dan Teknologi Akselerator, BATAN \\ Jl. Babarsari Kotak Pos 6101 Ykbb, Yogyakarta 55281 \\ e-mail: ri_sij@yahoo.com
}

Diterima 07 Januari 2014, diterima dalam bentuk perbaikan 06 Oktober 2014, disetujui 12 Mei 2015

\begin{abstract}
ABSTRAK
STUDI KRITIKALITAS REAKTOR RISET DAYA RENDAH BERBAHAN BAKAR U ${ }_{3} \mathrm{Si}_{2} A$ I. Kegiatan ini sebagai kajian awal untuk modifikasi teras reaktor TRIGA, atau membangun reaktor riset daya rendah dengan bahan bakar $\mathrm{U}_{3} \mathrm{Si}_{2} \mathrm{Al}$ produksi dalam negeri. Studi kritikalitas ini menggunakan konfigurasi teras $4 \times 4$ terdiri 12 perangkat bahan bakar (FA) dan 4 perangkat bahan bakar-kendali (CFA) di mana perangkat bahan bakar-kendali ditempatkan di tengah. Tingkat kekritisan (besarnya $k_{e f}$ ) teras reaktor dihitung dengan program MCNP-4C untuk teras dengan tinggi bahan bakar $60 \mathrm{~cm}$. Tingkat kekritisan tersebut juga dihitung untuk beberapa kondisi teras reaktor yaitu semua bahan penyerap neutron di dalam, di luar teras dan sebagian di luar teras dan lainnya posisinya di atur sebagai simulasi kondisi kritis saat operasi reaktor. Dari hasil perhitungan kekritisan dengan kondisi semua penyerap di luar teras, di dalam teras diperoleh harga faktor perlipatan neutron efektif $\left(k_{e f}\right)$ masing-masing 1,0104; 0,74232 dan untuk sebagian penyerap di luar teras dan sebagian lainnya di dalam teras diperoleh harga faktor perlipatan neutron 1,001. Berdasar hasil studi ini konfigurasi teras $4 \times 4$ dengan perangkat bahan bakar $\mathrm{U}_{3} \mathrm{Si}_{2}$-Al dapat digunakan untuk modifikasi teras reaktor TRIGA atau membangun reaktor riset daya rendah baru.
\end{abstract}

Kata kunci: MCNP, $U_{3} \mathrm{Si}_{2}-\mathrm{Al}$, reaktor

\section{ABSTRACT}

CRITICALITY STUDY of LOW POWER RESEARCH REAKTOR WITH U $\mathrm{U}_{3} \mathrm{Si}_{2} \mathrm{Al}$ FUEL. This activity is a preliminary assessment to modify TRIGA reactor core, or to construct the new research reactor using $U_{3} \mathrm{Si}_{2} \mathrm{Al}$ Indonesian fuel assembly production. Criticality study carried out by using $4 \times 4$ core configuration, consist of 12 Fuel Assemblies (FAs) and 4 Control Fuel Assemblies CFAs), where the fourth CFAs placed on the middle. Core Criticality level (kef value) is calculated using MCNP4C for core with $60 \mathrm{~cm}$ fuel plate height. Criticality is calculated for various conditions, i.e all of neutron absorbers inserted, withdrawn and a part of them withdrawn and the other part are inserted to simulate of reactor operation. The result shown that multiplication factor with all of the neutron absorbers withdrawn and inserted are 1.0104 and 0.707 respectively and when a part is withdrawn and the other is inserted the multiplication factor is 1.0013. Based on this study, $4 \times 4 \mathrm{U}_{3} \mathrm{Si}_{2}$-Al fuel assemblies' core configuration could be used to modify TRIGA reactor core or construct the new low power research reactor.

Keywords: MCNP, $U_{3} \mathrm{Si}_{2}-\mathrm{Al}$, reactor

\section{PENDAHULUAN}

K

eberadaan reaktor riset di Indonesia masih diperlukan terutama untuk pelatihan dan penelitian, saat ini ada tiga reaktor riset yang beroperasi. Dua reaktor riset jenis TRIGA masing-masing berdaya 100 dan $2000 \mathrm{~kW}$, satu reaktor riset jenis Material Test Reactor (MTR) berdaya $30 \mathrm{MW}$. Untuk reaktor TRIGA ada kemungkinan akan mengalami kesulitan pengadaan bahan baru dikemudian hari, baik dari segi produksi bahan bakar maupun dari segi dana pembelian bahan bakar yang mahal. Sebagai antisipasi hal tersebut maka ada pemikiran untuk memodifikasi teras reaktor TRIGA dengan menggunakan bahan bakar jenis plat $\mathrm{U}_{3} \mathrm{Si}_{2}-\mathrm{Al}$, produksi PT INDUSTRI NUKLIR INDONESIA (PT INUKI).

Studi kekritisan adalah salah satu kegiatan yang harus dilakukan dalam perancangan reaktor nuklir. Hasil kegiatan ini akan diperoleh dimensi reaktor dan massa kritis reaktor dan juga parameter reaktor lainnya. Berdasar 
parameter reaktor yang diperoleh dari hasil studi kekritisan tersebut selanjutnya dapat digunakan sebagai dasar untuk analisis termohidrolik, yang merupakan bagian tak terpisahkan dalam kegiatan perancangan reaktor nuklir.

Sejak era bahan bakar pengayaan tinggi dilarang maka banyak reaktor riset jenis "Material Testing Reactor" mengkonversi dari bahan bakar pengayaan tinggi (HEU) ke pengayaan rendah (LEU) dengan menggunakan $\mathrm{U}_{3} \mathrm{Si}_{2}$-Al sebagai bahan bakar. Reaktor Riset PETTEN di Belanda, Perancis JHR dan Jerman FRMII demikian juga pengalaman Argentina telah menggunakan bahan bakar plat $\mathrm{U}_{3} \mathrm{Si}_{2}-\mathrm{Al}(1,2,3,4,5)$. Keberhasilan PT INUKI memproduksi perangkat bahan bakar dan perangkat kendali yang telah diuji dan digunakan di Pusat Reaktor Serba Guna (PRSG) GA Siwabessy ${ }^{(5)}$, menjadi dasar pemikiran untuk desain reaktor riset daya rendah berbahan bakar plat. Dengan demikian akan diperoleh kemandirian dalam pengadaan reaktor riset di Indonesia.

Dalam studi kekritisan teras reaktor ini dimensi teras reaktor disesuaikan dengan dimensi reaktor TRIGA sehingga tidak merubah reflektor atau tetap menggunakan reflektor yang ada. Teras reaktor baru TRIGA merupakan teras kompak, hanya berisi perangkat bahan bakar dan kendali sebagai mana reaktor OPAL di Australia ${ }^{(5)}$, di mana di dalam teras tidak ada fasilitas iradiasi sebagaimana di PRSG GA Siwabessy. Berdasar pengalaman tentang desain teras dengan bahan bakar $\mathrm{U}_{3} \mathrm{Si}_{2}-\mathrm{Al}$, kondisi kritis ada yang menggunakan model teras $3 \times 3$ atau dengan 9 perangkat bahan bakar ${ }^{(6)}$. Model teras reaktor daya rendah terdiri 16 perangkat bahan bakar dan kendali dalam matrik $4 \times 4$, dengan 12 perangkat bahan bakar dan 4 perangkat bahan bakar-kendali di tengah diharapkan dapat mencapai kritis. Perangkat bahan bakar terdiri dari 20 plat, tebal daging $0,055 \mathrm{~cm}$, tebal kelongsong $0,0375 \mathrm{~cm}$, dan celah antara dua plat bahan bakar $0,2 \mathrm{~cm}$, perkayaan $19,75 \%$. Perangkat bahan bakar-kendali terdiri dari 13 plat bahan bakar dan 2 bahan penyerap $B_{4} C$ pada kedua tepinya, tebal $B_{4} C 0,5 \mathrm{~cm}$ (5). Plat-plat bahan bakar dalam "kotak" dengan ukuran $6,4 \times 6,6 \times 69 \mathrm{~cm}^{3}$, "kotak" untuk perangkat bahan bakar dan kendali ukurannya sama. Kotak dari bahan Alumunium, kedua sisinya tebal $5,5 \mathrm{~mm}$ di mana plat bahan bakar ditempatkan dan dua sisi yang lain tebal $2 \mathrm{~mm}$, seperti disajikan pada Gambar 1 dan Gambar 2. Teras reaktor terdiri dari 12 perangkat bahan bakar dan 4 perangkat bahan bakar-kendali, dalam posisi $4 \times 4$, dengan perangkat bahan bakar-kendali diletakkan di tengah.

Model perangkat bahan bakar dan perangkat kendali didesain bagian atas dan bawah mempunyai luas permukaan sama supaya memperoleh luasan permukaan aliran pendingin yang sama antara bagian bawah dan atas. Dengan demikian proses perpindahan panas dari bahan bakar ke pendingin secara konveksi alam dapat berjalan dengan baik.

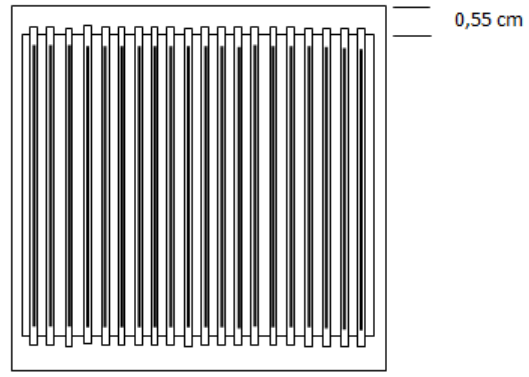

Gambar 1. Perangkat bahan bakar.

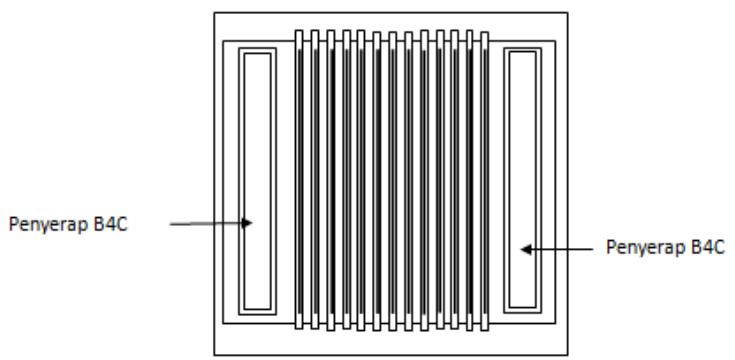

Gambar 2. Susunan bahan bakar- penyerap pada perangkat bahan bakar penyerap. 
Kondisi kekritisan dihitung dengan program MCNP4C (7). Tingkat kekritisan dihitung pada kondisi sebagai berikut.

a. 8 penyerap dari 4 perangkat kendali di luar teras

b. 8 penyerap dari 4 perangkat kendali di dalam teras

c. 4 penyerap dari 2 perangkat kendali berada di luar teras dan 4 penyerap perangkat kendali lainnya diatur posisinya sebagai simulasi kondisi operasi supaya diperoleh kondisi kritis dengan nilai faktor perlipatan neutron efektif mendekati 1.

Data teknis perangkat bahan bakar dan perangkat bahan bakar-kendali yang digunakan dalam perhitungan kekritisan disajikan pada Tabel 1.

Tabel 1. Data teknis Perangkat bahan bakar dan Perangkat kendali.

\begin{tabular}{clc}
\hline No. & Perangkat bahan bakar/Perangkat kendali & Dimensi \\
\hline 1. & Tebal kelongsong Al & $0,0375 \mathrm{~cm}$ \\
\hline 2. & Tebal daging $\mathrm{U}_{3} \mathrm{Si}_{2}$ & $0.055 \mathrm{~cm}$ \\
\hline 3 & Densitas & $4,8 \mathrm{~g} \mathrm{U} / \mathrm{cm}^{3}$ \\
\hline 4. & Perkayaan $\mathrm{U}_{235}$ & $19.75 \%$ \\
\hline 5. & Celah antara dua plat bahan bakar & $0,2 \mathrm{~cm}$ \\
\hline 6. & Tebal struktur penopang plat bahan bakar & $0,55 \mathrm{~cm}$ \\
\hline 7. & Tebal struktur penutup sisi perangkat bahan bakar & $0,2 \mathrm{~cm}$ \\
\hline 8. & Tebal penyerap neutron $\mathrm{B}_{4} \mathrm{C}$ & $0,5 \mathrm{~cm}$ \\
\hline
\end{tabular}

Dalam studi kekritisan digunakan program MCNP di mana telah banyak diguanakan dalam analisis atau desain teras reaktor $(8,9,10,11,12)$. Dari hasil studi diharapkan dapat digunakan sebagai bahan pertimbangan dan kajian analisis keselamatan teras reaktor untuk pengganti teras TRIGA atau yang layak untuk dibangun jika akan membangun reaktor riset baru.

\section{METODOLOGI}

Dalam studi kritikalitas teras reaktor riset daya rendah berbahan bakar plat ini alat yang digunakan adalah Laptop dan program MCNP4C. Kritikalitas dihitung dengan model teras kompak (teras hanya berisi bahan bakar dan perangkat kendali), reflektor grafit dan pendingin air. Gambar 3 adalah model pola pemuatan perangkat bahan bakar dan perangkat bahan bakar-kendali teras reaktor dan reflektor berada dalam kolam seperti reaktor TRIGA. Perangkat bahan bakar dalam teras disusun dengan jarak antar perangkat bahan bakar satu dengan lainnya $4 \mathrm{~mm}$. Berdasar konsep Reaktor TRIGA dan ukuran perangkat bahan bakar dan perangkat kendali tersebut maka dibuat data input program MCNP. Data terdiri dari sel-sel yang mendefinisikan perangkat bahan bakar dan perangkat kendali, reflektor, air pendingin dan tangki reaktor. Berkas input digunakan sebagai masukan pada saat eksekusi program MCNP. Eksekusi program tidak dapat sekali langsung jalan, karena ada kesalahan pada berkas input, jika demikan maka berkas input dibetulkan dan dieksekusi lagi. Langkah tersebut dikerjakan sampai eksekusi program berhasil (tidak mengalami penghentian sebelum seluruh data masukan diproses). Perhitungan kekritisan dilakukan dengan kondisi teras reaktor sebagai berikut:

a. seluruh penyerap ditarik dari teras reaktor

b. semua penyerap di dalam teras reaktor dan

c. dua perangkat penyerap, dua perangkat penyerap di luar teras dan dua perangkat penyerap diatur posisinya dalam teras untuk simulasi kondisi operasi. 
Kondisi kritis untuk kondisi (a) dan (b) digunakan untuk analisis keselamatan reaktor, kondisi (b) untuk mengetahui tingkat subkrikitiknya, sedangkan kondisi kritis untuk kondisi (c) sebagai simulasi operasi, digunakan untuk perhitungan fluks neutron dan pembangkitan panas pada saat reaktor beroperasi.

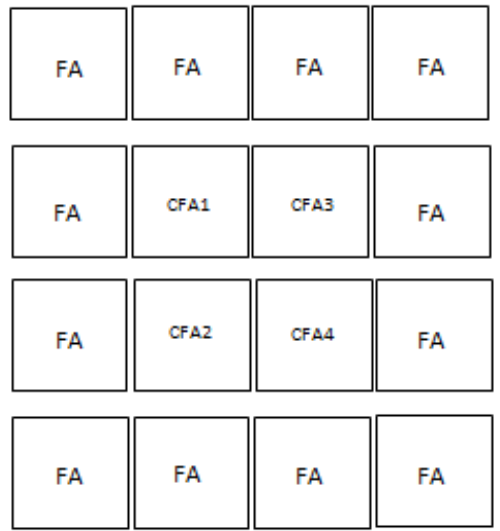

FA : perangkat bahan bakar

CFA: perangkat bahan bakar-kendali

Gambar 3. Susunan bahan bakar dan bahan bakar-kendali dalam teras.

\section{HASIL DAN PEMBAHASAN}

Gambar 4 adalah gambar susunan teras, reflektor dilihat dari atas dan Gambar 5 adalah susunan tangki reaktor (sebagian), teras, reflektor dan air tangki reaktor dilihat dari samping. Kedua gambar tersebut merupakan output Visual Edition dari data input program MCNP yang digunakan untuk perhitungan kekritisan. Suatu data input program MCNP itu benar jika dieksekusi dengan Visual Editor dapat menghasilkan gambar yang benar.

Kekritisan dihitung dengan "running" program MCNP dengan data input sesuai dengan kondisi teras, yaitu kondisi semua penyerap di atas teras, di dalam teras, dan kondisi simulasi operasi reaktor di mana dua perangkat bahan bakar-penyerap, keempat bahan penyerap ditarik dari teras dan dua perangkat lainnya keempat penyerapnya ditarik sampai diperoleh kondisi kritis.

Sesuai perkiraan awal bahwa kondisi kritis dapat dicapai dengan konfigurasi teras $4 \times 4$ perangkat bahan bakar sebagaimana juga reaktor OPAL di Australia yang menggunakan konfigurasi teras $4 \times 4$ untuk daya reaktor yang lebih tinggi karena bahan bakarnya juga lebih tinggi dimensinya.

Dari hasil perhitungan kekritisan diperoleh harga-harga faktor perlipatan neutron efektif untuk kondisi semua penyerap di atas teras dan di dalam teras masing-masing adalah 1,01403 dan 0,70794. Untuk kondisi simulasi operasi di mana dua perangkat kendali CFA1 dan CFA4 semua pnyerapnya di tarik ke atas teras, sedangkan penyerap pada CFA2 dan CFA3 diatur posisinya sehingga diperoleh harga faktor perlipatan efektip mendekati 1 $(0,99)$. Kondisi kritis simulasi operasi reaktor tercapai ketika penyerap dari CFA2 dan CFA3 ditarik $50 \mathrm{~cm}$ dari dasar atau pada posisi ketinggian $83 \%$, dengan harga faktor perlipatan neutron efektif 1,0013 , yang berarti sedikit di atas 1 maka dengan mengatur posisi (menurunkan penyerap misalnya menjadi 49) maka menjadi 1 (reaktor kondisi kirtis).

Tabel 2. Hasil perhitungan kekritisan.

\begin{tabular}{clc}
\hline No. & Posisi Penyerap neutron / batang kendali & Nilai kefektif \\
\hline 1. & Semua penyerap neutron ditarik dari teras & 1,01403 \\
\hline 2. & Semua penyerap di dalam teras & 0,70794 \\
\hline 3. & $\begin{array}{l}\text { 4 penyerap dari CFA1 dan CFA4 ditarik dari teras, 4 penyerap dari CFA2 } \\
\text { dan CFA3 sebagian ditarik dari teras }\end{array}$ & 1,0013 \\
\hline
\end{tabular}


Berdasar pengalaman pengoperasian reaktor Kartini selama ini, kondisi operasi dengan posisi penyerap yang tersisa dalam teras $17 \%$, menunjukkan bahwa reaktivitas lebih teras tidak besar. Dari hasil perhitungan kekritisan dengan kondisi semua penyerap ditarik dari teras dengan harga faktor perlipatan neutron efektif 1,01094, berdasar teori reaktor (7) berarti reaktivitas lebih teras adalah 0,01904 atau setara dengan 2,9 dollar. Harga reaktivitas lebih ini yang akan menentukan umur reaktor, (siklus penggantian bahan bakar) semakin besar reaktivitas lebih maka makin lama umur operasi dari reaktor tersebut. Hal tersebut dikarenakan ketika reaktor dioperasikan maka akan terjadi penyusutan bahan bakar, adanya umpan balik reaktivitas (negative), dan juga terbentuknya racun (isotop hasil belah yang mempunyai tampang lintang serapan besar terhadap neutron termal ), ketiga kondisi tersebut akan dapat diatasi jika reaktivitas lebih teras masih memadai/mampu mengimbangi reaktivitas negatif yang terjadi. Untuk kondisi penyerap di dalam teras dengan faktor perlipatan neutron efektif 0,70794 berarti tingkat subkritiknya sangat tinggi, berarti tingkat keselamatan kondisi shutdown tinggi juga ( jauh dari kondisi kecelakaan kritis saat penyerap di dalam teras reaktor). Bahan bakar $\mathrm{U}_{3} \mathrm{Si}_{2}-\mathrm{Al}$ pengayaan rendah telah digunakan diberbagai Negara yang mengkonversi bahan bakar dari pengkayaan tinggi ke pengkayaan rendah $(9,10,11)$.

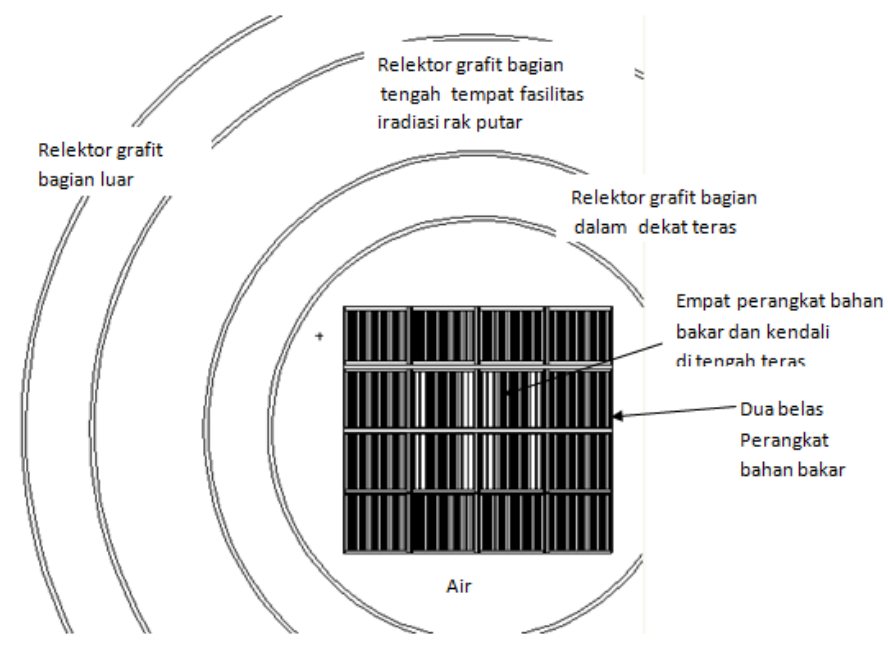

Gambar 4. Teras dan reflektor tampak dari atas.

\section{KESIMPULAN}

Dari hasil studi kekritisan teras reaktor daya rendah dengan bahan bakar $\mathrm{U}_{3} \mathrm{Si}_{2}-\mathrm{Al}$ dapat disimpulkan bahwa teras reaktor dengan konfigurasi $4 \times 4$ perangkat bahan bakar dan tinggi bahan bakar $60 \mathrm{~cm}$ dapat mencapai kritis, sehingga dapat digunakan sebagai pertimbangan untuk modifikasi teras reaktor TRIGA.

\section{UCAPAN TERIMA KASIH}

Kami mengucapkan terima kasih kepada Kepala Bidang Reaktor dan Kepala Sub Bidang Operasi dan Perawatan Reaktor yang telah memberikan kepercayaan dan fasilitas untuk melaksanakan kegiatan penelitian ini.

\section{DAFTAR PUSTAKA}

1. P.J.M. THIJSSEN, HEU/LEU CONVERSION OF THE PETTEN HFR, Proceeding Research Reactor Fuel Management 2006 Transaction, $10^{\text {th }}$ International Meeting Research Reactor Management, Sofia Bulgaria, 30 April-30 May (2006)

2. MC.ANSELMET, P.LEMOINE, D IRACANE, E. KOONEN, P. BENOIT, I. CAILUERE, P. COLOMB, T.PIN, S. BRISSON, S. GUILOT, QUALIFICATION PROGRAM For JHR FUEL ELEMENT, Proceeding Research Reactor Fuel Management 2009 Transaction, Vienna, Austria, 22-25 March (2009) 
3. A. ROHRMOSER, W PETRY, Fuel Plate Temperature during Operation of FRM II, Research Reactor Fuel Management 2009 Transaction, Vienna, Austria, 22-25 March (2009)

4. VILARINO, A. DOVAL, Project Report INVAP's Research Designs, Hindawi Publishing Corporation, Science and Technology of Nuclear Installations, Article ID 490391, Vol. (2011) 1- 6

5. VILARINO, Core Improvement Performance Using $\mathrm{U}_{3} \mathrm{Si}_{2}$-Al Fuel in the RP-10 Modernization, Proceeding 2011-33rd International Meeting Reduced Enrichment for Research and Test Reactor, Marriot Santiago Hotel, Santiago, Chile, October 23-27 (2011)

6. LA-12625-M, Version 4B Manual, MCNP-A General Monte Carlo N-Particle Transport Code, Los Alamos National Laboratory, March (1997)

7. DUDERSTADT J.J, HAMILTON L.J, Nuclear Reactor Analysis, JOHN WILEY and SONS. Inc, New York, (1976)

8. MOUSTAFA AZIZ and MOHGA HASSAN, Modeling and Analysis of Conversion HEU-LEU for IAEA Research Reactor, Arab Journal of Nuclear Science and Applications, Cairo, Egypt, 46(4), (2013) 182-188

9. VAN DEN BERGHER SVEN, LEENAERS ANN, KOONEN EDGAR, SANNEN LEO, Advances in Science and Technology, Switzerland, Vol. 73, (2010) 78-90

10. KOMIL NEAMATI, NASER MANSOUR SHARIFLOO, Investigation the Feasibility of Alternative $\mathrm{U}_{3} \mathrm{Si}_{2}-\mathrm{Al}$ fuel for the Tehran Research Reactor Compared to the Neutron Multiplication Factor, Journal of Basic and Applied Scientific Research, Tehran, Iran, 3(2s), (2013) 260-263

11. RAFAEL OR MUNIZ, DOUGLAS B DOMINGOS, ADIMIS DOS SANTOS, ANTONIO T. E SILVA, THIAGO G JOSE, VITOR O. ARIDES, International Nuclear Alliance Conference-INAC 2013 Reafe PE Brazil, November (2013) 24-29

12. SHEN XIUZHONG, NAKAJIMA KEN, UNESAKI HIRONOBU, MISHINA KAICHIRO, Reactivity Insertion Transient Analysis for KIYOTO UNIVERSITY REACTOR Low Enriched Uranium Silica Fuel Core, Journal Article Annals of Nuclear Energy, Elsevier Ltd. 62, (2013) 